\title{
Editorial
}

\section{Epilepsy, Behavioral Problems, and Intellectual Disability among Children in India: Conundrums and Challenges}

A research paper, "Behavioral problems and IQ changes in pediatric epilepsy: A case-control study" ${ }^{[1]}$ included in this volume attracts attention to the association between epilepsy and behavioral problems, and its impact on intelligent quotient (IQ) among young children in India. Does epilepsy have an association with IQ? Does epilepsy have an association with behavioral problems? Do behavioral problems, epilepsy, and low IQ interact with each other? These are some of the many questions that need to be closely examined.

Worldwide, 70 million people suffer from epilepsy. ${ }^{[2]}$ About 33 million children with epilepsy suffer from various types of behavioral problems, and from these $90 \%$ of the children reside in developing countries. ${ }^{[3]}$ Over 12 million people are estimated to have some form of epilepsy in India..$^{[2]}$ Disability-adjusted life years lost due to epilepsy from a study in India in 2007-2008 placed it at $846.96 / 100,000 \cdot{ }^{[4]}$ In a study conducted among poor rural population in India, over $23.7 \%$ of the children with intellectual disability were found to have some type of epilepsy, and $80.7 \%$ behavioral problems coexisted. ${ }^{[5]}$ In developing countries, very few studies have been conducted on the relationship between epilepsy, IQ, and behavioral problems. ${ }^{[6,7]}$

While research continues to investigate prevalence related interconnections between pediatric epilepsy with the typology of behavioral problems and its negative impact on IQ, we should be cognizant about the larger research lacunae that confront us at the national level in India on this topic. For example, we do not have estimates of the prevalence of epilepsy, behavioral problems, and intellectual disability together from a nationally representative sample. Further, there is lack of prevalence data of epilepsy, behavioral problems, and IQ levels respective to factors such as severity, age, gender, place of living, etc., An association between IQ, behavioral problems, and epilepsy has been suggested in some studies from developed countries. ${ }^{[8-10]} \mathrm{A}$ complex interconnection of neurological, psychological, educational, and social pathology behind these disorders presents a serious challenge for developing effectual interventions. A strong disabling stigma attached separately with epilepsy, behavioral problems, and lower levels of IQ further complicate interventional efforts at all levels.

Among people with intellectual disability of genetic etiology, the stereotype, self-injurious, aggressive, or destructive behaviors may be a manifestation of unrecognized seizure activity. ${ }^{[1]}$ Most behavioral problems among children with intellectual disability can be treated with behavior modification approaches, and in a few cases, in combination with pharmacological therapies. By treating behavioral problems among this population, can we reduce the risk of epilepsy and a lowering effect on IQ; such questions warrant further explorative research.

Full Scale Intelligence Quotient scale has shown to make significantly lower estimates of intellectual ability in people with epilepsy. ${ }^{[12]}$ Hence, a word of caution is mandatory, when introducing IQ as a factor into intellectual disability and behavioral functioning. Changing behaviors assume some level of intelligence, to receive information, process it, and make decisions that result in adaptive behavior. Research studies show that IQ tests seem to be biased in both the tester and the tested. ${ }^{[13]}$ Thus, the tools themselves pose a challenge. Therefore, looking at IQ as a determinant among the intellectually disabled may be problematic.

While we do not have a clear understanding of the prevalence of children suffering from epilepsy, behavioral problems, and low IQ combined, but it is generally accepted that the prevalence is high enough to label it as a significant public health concern for the nation. Stigma and resultant psychological issues are hindrances for children with epilepsy ${ }^{[14,15]}$ intellectual disability, and behavioral problems ${ }^{[16,17]}$ to actively participate in many activities in their lives and adversely affect their quality of life. ${ }^{[9]}$ The social and physical isolation and discrimination due to stigma not only limit their chances of learning new skills and mastering learned skills but also limit the opportunity of recovering and improving in their lives. Issues related with stigma and isolation are rarely addressed in current medical and rehabilitation practices in India. ${ }^{[14]}$ More research is needed to develop public health models and strategies to combat the social stigma and its negative impact on the condition.

Ram Lakhan, Olúgbémiga T. Ekúndayò ${ }^{1}$, Manoj Sharma ${ }^{2}$

Department of Health and Human Performance, Berea College, Berea, 'Department of Allied Health College of Health Professions, Northern Kentucky University, Kentucky, ${ }^{2}$ Department of Behavioral and Environmental Health, School of Public Health, Jackson State University, Jackson, Mississippi, USA 
Address for correspondence: Dr. Ram Lakhan, Department of Health and Human Performance, CPO 2187, Seabury Centre \#229, Berea College, Berea, Kentucky, USA.

E-mail: lakhanr@berea.edu

\section{REFERENCES}

1. Lakhan R, Ekúndayò OT, Sharma M. Epilepsy, behavioral problems, and intellectual disability among children in India: Conundrums and challenges. J Neurosci Rural Pract 2018;9:1-2.

2. Amudhan S, Gururaj G, Satishchandra P. Epilepsy in India I: Epidemiology and public health. Ann Indian Acad Neurol 2015;18:263-77.

3. Datta SS, Premkumar TS, Chandy S, Kumar S, Kirubakaran C, Gnanamuthu C, et al. Behaviour problems in children and adolescents with seizure disorder: Associations and risk factors. Seizure 2005;14:190-7.

4. Banerjee TK, Dutta S, Ray BK, Ghosal M, Hazra A, Chaudhuri A, et al. Epidemiology of epilepsy and its burden in Kolkata, India. Acta Neurol Scand 2015;132:203-11.

5. Lakhan R. The coexistence of psychiatric disorders and intellectual disability in children aged 3-18 years in the Barwani district, India. ISRN Psychiatry 2013;2013:875873.

6. Lakhan R. Intelligence quotient is associated with epilepsy in children with intellectual disability in India. J Neurosci Rural Pract 2013;4:408-12.

7. Kariuki SM, Abubakar A, Holding PA, Mung'ala-Odera V, Chengo E, Kihara M, et al. Behavioral problems in children with epilepsy in rural Kenya. Epilepsy Behav 2012;23:41-6.

8. Buelow JM, Perkins SM, Johnson CS, Byars AW, Fastenau PS, Dunn DW, et al. Adaptive functioning in children with epilepsy and learning problems. J Child Neurol 2012;27:1241-9.

9. Reilly C, Atkinson P, Das KB, Chin RF, Aylett SE, Burch V, et al. Neurobehavioral comorbidities in children with active epilepsy: A population-based study. Pediatrics 2014;133:e1586-93.

10. van Iterson L, Zijlstra BJ, Augustijn PB, van der Leij A, de Jong PF. Duration of epilepsy and cognitive development in children: A longitudinal study. Neuropsychology 2014;28:212-21.
11. Kerr M, Gil-Nagel A, Glynn M, Mula M, Thompson R, Zuberi SM, et al. Treatment of behavioral problems in intellectually disabled adult patients with epilepsy. Epilepsia 2013;54 Suppl 1:34-40.

12. Baxendale S, McGrath K, Thompson PJ. Epilepsy \&amp; IQ: The clinical utility of the wechsler adult intelligence scale-fourth edition (WAIS-IV) indices in the neuropsychological assessment of people with epilepsy. J Clin Exp Neuropsychol 2014;36:137-43.

13. Duckworth AL, Quinn PD, Lynam DR, Loeber R, Stouthamer-Loeber M. Role of test motivation in intelligence testing. Proc Natl Acad Sci U S A 2011;108:7716-20.

14. Thomas SV, Nair A. Confronting the stigma of epilepsy. Ann Indian Acad Neurol 2011;14:158-63.

15. de Boer HM, Mula M, Sander JW. The global burden and stigma of epilepsy. Epilepsy Behav 2008;12:540-6.

16. Jahoda A, Wilson A, Stalker K, Cairney A. Living with stigma and the self-perceptions of people with mild intellectual disabilities. J Soc Issues 2010;1:521-34.

17. Werner S, Corrigan P, Ditchman N, Sokol K. Stigma and intellectual disability: A review of related measures and future directions. Res Dev Disabil 2012;33:748-65.

This is an open access article distributed under the terms of the Creative Commons Attribution-NonCommercial-ShareAlike 3.0 License, which allows others to remix, tweak, and build upon the work non-commercially, as long as the author is credited and the new creations are licensed under the identical terms.

\begin{tabular}{|l|l|}
\hline \multicolumn{2}{|c|}{ Access this article online } \\
\hline Quick Response Code: & Website: \\
\hline & www.ruralneuropractice.com \\
& \\
& \\
\end{tabular}

How to cite this article: Lakhan R, Ekúndayò OT, Sharma M. Epilepsy, behavioral problems, and intellectual disability among children in India: Conundrums and challenges. J Neurosci Rural Pract 2018;9:1-2. 